\title{
FACTORES CLAVE EN PROCESOS DE BIORREMEDIACIÓN PARA LA DEPURACIÓN DE AGUAS RESIDUALES. UNA REVISION
}

\section{KEY FACTORS IN BIOREMEDIATION PROCESSES FOR THE WASTEWATER TREATMENT. A REVIEW}

\author{
Óscar Ome Barrera ${ }^{1}$, Carlos Zafra Mejía ${ }^{2}$
}

${ }^{1}$ Ingeniero Ambiental, M.Sc. en Desarrollo Sustentable y Gestión Ambiental, Facultad de Medio Ambiente y Recursos Naturales. Universidad Distrital Francisco José de Caldas, Avda. Circunvalar Venado de Oro, Bogotá D.C., Colombia. Tel.: +57 1 3239300, ext. 4010, e-mail: danilo8912@hotmail.com, iDhttps://orcid.org/0000-0002-3577-2794; ${ }^{2}$ Ingeniero Civil, Ph.D. en Ingeniería Ambiental, Maestría en Desarrollo Sustentable y Gestión Ambiental, Facultad de Medio Ambiente y Recursos Naturales. Universidad Distrital Francisco José de Caldas, Avda. Circunvalar Venado de Oro, Bogotá D.C., Colombia. Tel.: +57 13239300, ext. 4040, fax: +57 1 2841658, e-mail: czafra@udistrital.edu.co, (iDhttps://orcid.org/0000-0002-4061-4897

\author{
Rev. U.D.C.A Act. \& Div. Cient. 21(2): 573-585, Julio-Diciembre 2018 \\ https://doi.org/10.31910/rudca.v21.n2.2018.1037
}

Artículo de acceso abierto publicado por Revista U.D.C.A Actualidad \& Divulgación Científica bajo

una licencia Creative Commons CC BY-NC 4.0

\section{RESUMEN}

La biorremediación ha demostrado ser una alternativa para establecer nuevos sistemas de depuración de aguas residuales y optimizar los sistemas convencionales existentes. El objetivo de este artículo de revisión es identificar y analizar los factores clave en procesos de biorremediación para la depuración de aguas residuales, a nivel mundial. Se utilizó un método de revisión sistemática de literatura, que incluyó un índice de frecuencia de citación mediante cuartiles $(Q)$. Los resultados most raron la existencia de seis factores clave en procesos de biorremediación para la depuración de aguas residuales: $\mathrm{pH}(\mathrm{Q} 3)>$ temperatura $(\mathrm{Q} 2)>$ oxígeno (Q2) > nitrógeno (Q2) > fósforo (Q1) > $\mathrm{DBO}_{5}(\mathrm{Q} 1)$. No existieron diferencias significativas entre las tecnologías de bioaumentación y bioestimulación en relación a los seis factores clave identificados. No se evidenció, en el ámbito mundial, una tendencia en el uso de alguna de estas dos tecnologías; sin embargo, en Asía, Europa y Norte América, se detectó un mayor número de reportes en el uso de la tecnología de bioaumentación y, en Sur América y África, existió mayor empleo de la tecnología de bioestimulación. Las tecnologías de biorremediación (Q1), probablemente, se encontraron en una fase inicial de desarrollo y aplicación en sistemas de depuración para aguas residuales, debido a que las tecnologías químicas (Q2) y físicas (Q2) presentaron un mayor reporte, a nivel mundial. Finalmente, los resultados de esta revisión son un punto de referencia para las institu- ciones ambientales, encargadas del control de la calidad del agua y diseñadores y operadores en sistemas de depuración.

Palabras clave: aguas residuales, bioaumentación, bioestimulación, Biorremediación, fitorremediación.

\section{ABSTRACT}

Bioremediation has proven to be an alternative to establishing new wastewater treatment systems and optimizing the existing conventional systems. The objective of this review paper is to identify and analyze the key factors in bioremediation processes for wastewater treatment worldwide. A systematic review method of literature was used, which included a citation frequency index using quartiles $(Q)$. The results showed the existence of six key factors in bioremediation processes for wastewater treatment: $\mathrm{pH}(\mathrm{Q} 3)>$ temperature (Q2) > oxygen (Q2) > nitrogen $(\mathrm{Q} 2)>$ phosphorus $(\mathrm{Q} 1)>$ $\mathrm{BOD}_{5}(\mathrm{Q} 1)$. There were no significant differences between bioaugmentation and biostimulation technologies in relation to the six key factors identified. A trend in the use of some of these technologies was not demonstrated at the global level. However, in Asia, Europe, and North America there was a greater report on the use of bioaugmentation technology; and in South America and Africa, there was a greater report of biostimulation technology. Bioremediation technologies (Q1) were probably in an initial phase of development and application in wastewater treatment systems because 
chemical (Q2) and physical technologies (Q2) presented a larger worldwide report. Finally, the results of this study are a reference point for environmental institutions responsible for water quality control, and designers and supervisors in water treatment systems.

Keywords: bioremediation, wastewater, bioaugmentation, biostimulation, phytoremediation.

\section{INTRODUCCIÓN}

Las tecnologías convencionales para la depuración de aguas residuales suelen ser ambientalmente no sostenibles y costosas durante su operación (Saratale et al. 2011). A menudo, se observa que estas tecnologías requieren ser optimizadas o sustituidas; por ejemplo, en un estudio realizado a 50 empresas en EE.UU., permitió evidenciar que la mayoría de las instalaciones para la depuración de aguas residuales requerían optimizar o cambiar sus sistemas tecnológicos, a fin de cumplir con la legislación establecida (Danalewich et al. 1998). A nivel mundial, en la última década, también se reporta una tendencia similar en sistemas convencionales para la depuración de aguas residuales (Guo et al. 2010; Chen et al. 2015).

El inadecuado tratamiento de las aguas residuales ha causado impactos ambientales al recurso hídrico y afectaciones sobre la salud pública (Wani et al. 2013). Al respecto, Lu et al. (2014) reportaron que los vertimientos de aguas residuales en China han causado híper-eutrofización en los cuerpos hídricos receptores, constituyéndose en un factor limitante para el desarrollo del país. Adicionalmente, Prevost et al. (2015) identificaron que las principales fuentes de contaminación viral en el río Sena (Francia) fueron los efluentes de las plantas para la depuración de aguas residuales, existiendo una relación significativa entre las afectaciones sobre la salud pública y la contaminación de las aguas superficiales.

A partir de lo anterior, es de interés creciente el estudio de nuevas tecnologías para la depuración de aguas residuales, con el objeto de incrementar la eficiencia en la eliminación de contaminantes y reducir los costos de operación asociados. La biorremediación ha demostrado ser una alternativa para establecer nuevos sistemas de depuración para aguas residuales y optimizar los sistemas convencionales (Chen et al. 2015). La bioestimulación, bioaumentación y fitorremediación son tecnologías de biorremediación eficaces para la eliminación de contaminantes, en una variedad de entornos (por ejemplo, aguas subterráneas, aguas residuales, suelo y lodos del petróleo) (Hassanshahian et al. 2013). Adicionalmente, estas tecnologías son de bajo costo económico e impacto ambiental, por su menor consumo energético y baja producción de lodo, en comparación, por ejemplo, con tecnologías de tratamiento físico-químico (Saratale et al. 2011; Das Gupta et al. 2016).

La biorremediación de aguas residuales se puede dividir en tres tecnologías principales (Salinas et al. 2008): (i) depuración natural, donde los contaminantes se reducen por la acción de microorganismos nativos sin ninguna ayuda externa; (ii) bioestimulación, en la cual, se incorporan nutrientes al sistema para acelerar la biodegradación y (iii) bioaumentación, en donde se añaden microorganismos especializados al sistema de tratamiento para incrementar su eficiencia. Adicionalmente, Wang et al. (2014) reportaron la fitorremediación como una tecnología potencial de biorremediación, donde plantas especializadas fueron capaces de absorber, almacenar o metabolizar los contaminantes presentes en las aguas residuales. Se ha reportado que los principales factores determinantes de estas tecnologías de biorremediación fueron el contenido de materia orgánica, oxígeno disuelto, temperatura, pH, nitrógeno y fósforo (Margesin et al. 1998; Sode et al. 2013; Tang et al. 2015).

Los sistemas de depuración para aguas residuales han tenido éxito mediante el uso de las principales tecnologías de biorremediación. La bioaumentación, se considera la tecnología más usual, debido a que proporciona cepas bacterianas especializadas, desarrolladas en ambientes óptimos y son seleccionadas según su capacidad de metabolizar contaminantes específicos del agua (Gong, 2012). En menor medida, se usa la tecnología de bioestimulación, ya que implica potenciar las capacidades de las bacterias nativas, requiriendo identificar una relación óptima de nutrientes (Hassanshahian et al. 2013); por ejemplo, Guo et al. (2010) reportaron que, para acelerar la puesta en marcha de procesos para la depuración biológica de aguas residuales en sistemas municipales del sur de China, se optó por la adición de bacterias especializadas antes que la bioestimulación con nutrientes. Chen et al. (2015) y Tang et al. (2015) evidenciaron que la incorporación de bacterias especializadas para la eliminación de nitrógeno fue exitosa para la depuración de aguas municipales en un sistema piloto en Henan (China) y en el tratamiento de aguas residuales en Pensylvania (USA), respectivamente. Kyriacou et al. (2005) y Rajendran et al. (2012) indicaron también que, mediante la adición de bacterias especializadas, lograron la remoción de $\mathrm{DQO}$ y $\mathrm{DBO}$ en el tratamiento de aguas residuales en Grecia y en Alemania, respectivamente.

El objetivo principal de esta revisión fue identificar y analizar los factores clave en procesos de biorremediación para la depuración de aguas residuales, a nivel mundial (1997-2016). Se estableció un orden de importancia para los factores clave, identificados según su frecuencia de citación en documentos científicos y se realizó un análisis comparativo entre las principales tecnologías de biorremediación y los siste- 
mas convencionales para la depuración de aguas residuales (física y química). Finalmente, se presenta un análisis de distribución geográfica, a nivel mundial, de las tecnologías de biorremediación identificadas.

\section{MATERIALES Y MÉTODOS}

Sistema de búsqueda bibliográfica. Se utilizaron las siguientes bases de datos para la revisión de literatura: (i) ScienceDirect, (ii) Scopus y (iii) Google Scholar. En la primera fase de búsqueda bibliográfica, se utilizaron las siguientes palabras clave en idioma inglés: (i) wastewater (aguas residuales) y (ii) bioremediation (biorremediación); estas palabras clave, se asumieron como principales descriptores temáticos. La búsqueda bibliográfica, se realizó entre 1997 y 2016 y sobre el contenido total de artículos y libros depositados en las tres bases de datos consultadas. En esta primera fase, se detectaron 30.400, 7.841 y 5.233 documentos en las bases de datos Google Scholar, ScienceDirect y Scopus, respectivamente (Tabla 1).

La segunda fase de revisión fue desarrollada para incluir palabras clave adicionales en idioma inglés, reportadas por la base de datos Scopus (descriptores temáticos: keywords). Estas palabras clave adicionales permitieron identificar los factores clave en procesos de biorremediación para la depuración de aguas residuales. A continuación, se listan las palabras clave detectadas (Tabla 1): (i) potencial de hidrógeno (pH-potential of hydrogen), (ii) temperatura (temperature), (iii) oxígeno (oxygen), (iv) nitrógeno (nitrogen), (v) fósforo (phosphorus) y (vi) demanda biológica de oxígeno (BOD-biologycal oxygen demand).

Sistema de análisis bibliográfico. Las bases de datos consultadas se utilizaron, con el fin de establecer un orden de importancia para los factores clave, identificados a partir de su frecuencia de citación en documentos científicos. Al respecto, se asumió que los factores clave más significativos en procesos de biorremediación para la depuración de aguas residuales fueron frecuentemente citados o reportados por las bases de datos consultadas; de esta manera, se estimó la importancia de las tecnologías y factores clave detectados, a través de su frecuencia de citación en documentos científicos. Aunque la anterior hipótesis no fue necesariamente cierta, fue usada durante la presente investigación bibliográfica, como un lineamiento de búsqueda y de análisis.

Se desarrolló un índice de frecuencia de citación $(Q)$, que relacionó el número de documentos detectados en la segunda y primera fase de la metodología de revisión utilizada. Se realizó, con el fin de establecer un orden de importancia mediante cuartiles para los factores clave detectados en procesos de biorremediación para la depuración de aguas residuales. El índice $(Q)$ tuvo una variación entre 0 y 1

Tabla 1. Orden de importancia para los factores clave identificados.

\begin{tabular}{|c|c|c|c|c|c|c|c|c|c|c|}
\hline \multirow{3}{*}{$\begin{array}{l}\mathscr{D} \\
\mathscr{m} \\
\text { L }\end{array}$} & \multirow{3}{*}{$\begin{array}{l}\text { Palabras clave } \\
\text { en idioma } \\
\text { inglés }\end{array}$} & \multicolumn{6}{|c|}{ Bases de datos } & \multirow{3}{*}{$\begin{array}{l}\text { Índice pro- } \\
\text { medio }(Q)\end{array}$} & \multirow{3}{*}{$\begin{array}{l}\text { Cuartil } \\
\text { Prome- } \\
\text { dio }\end{array}$} & \multirow{3}{*}{$\begin{array}{l}\text { Variación } \\
\text { del Cuartil }\end{array}$} \\
\hline & & \multicolumn{2}{|c|}{ ScienceDirect } & \multicolumn{2}{|c|}{ Scopus } & \multicolumn{2}{|c|}{ Google Scholar } & & & \\
\hline & & $\begin{array}{l}\text { Documen- } \\
\text { tos detecta- } \\
\text { dos }\end{array}$ & $\begin{array}{l}\text { Índice } \\
(Q)\end{array}$ & $\begin{array}{l}\text { Documen- } \\
\text { tos detecta- } \\
\text { dos }\end{array}$ & $\begin{array}{l}\text { Índice } \\
(Q)\end{array}$ & $\begin{array}{l}\text { Documentos } \\
\text { detectados }\end{array}$ & $\begin{array}{l}\text { Índice } \\
(Q)\end{array}$ & & & \\
\hline \multirow[t]{2}{*}{1} & \multirow{2}{*}{$\begin{array}{l}\text { Wastewater and } \\
\text { bioremediation }\end{array}$} & 7841 & 1,000 & 5233 & 1,000 & 30400 & 1,000 & - & - & - \\
\hline & & & & & & & & & & \\
\hline \multirow[t]{6}{*}{2} & $\mathrm{pH}$ & 5760 & $0,735^{\mathrm{a}}$ & 1260 & 0,241 & 18800 & 0,618 & 0,531 & Q3 & Q3, Q1, Q3 \\
\hline & Temperature & 5740 & 0,732 & 802 & 0,153 & 18300 & 0,602 & 0,496 & Q2 & Q3, Q1, Q3 \\
\hline & Oxygen & 4171 & 0,532 & 1206 & 0,230 & 18500 & 0,609 & 0,457 & Q2 & Q3, Q1, Q3 \\
\hline & Nitrogen & 3888 & 0,496 & 832 & 0,159 & 18500 & 0,609 & 0,421 & Q2 & Q2, Q1, Q3 \\
\hline & Phosphorus & 1388 & 0,177 & 401 & 0,077 & 14200 & 0,467 & 0,240 & Q1 & Q1, Q1, Q2 \\
\hline & $\mathrm{BOD}_{5}{ }^{\mathrm{c}}$ & 523 & 0,067 & 128 & 0,024 & 6040 & 0,199 & 0,097 & Q1 & Q1, Q1, Q1 \\
\hline \multirow[t]{4}{*}{3} & Wastewater & 397639 & 1,000 & 175846 & 1,000 & 1070000 & 1,000 & - & - & - \\
\hline & Chemical & 275717 & 0,693 & 67997 & 0,387 & 310000 & 0,290 & 0,457 & Q2 & Q3, Q2, Q2 \\
\hline & Physical & 162643 & 0,409 & 10831 & 0,062 & 363000 & 0,339 & 0,270 & Q2 & Q2, Q1, Q2 \\
\hline & Bioremediation & 7841 & 0,020 & 5233 & 0,030 & 30400 & 0,028 & 0,026 & Q1 & Q1, Q1, Q1 \\
\hline
\end{tabular}

Nota. ${ }^{a} 5760 / 7841=0,735 .{ }^{b}$ Variación del cuartil según la base de datos. ${ }^{\mathrm{C}}$ BOD $=$ Demanda biológica de oxígeno. 
(Zafra et al. 2017), siendo: (i) Q1, entre 0,0-0,25; (ii) Q2, entre 0,25-0,5; (iii) Q3, entre 0,5-0,75 y (iv) Q4, entre 0,75-1,0, es decir, Q4 representó los factores clave de mayor importancia o frecuencia de citación en los documentos científicos incluidos en las bases de datos consultadas (Tabla 1); por ejemplo, para el factor clave $\mathrm{pH}$, los documentos detectados en la segunda fase fueron 5.760 en relación con los 7.841 documentos detectados en la primera fase; de esta manera, el índice de citación Q fue 0,735 (5.760/7.841 = 0,735; Q4).

Posteriormente, se desarrolló una tercera fase de revisión, que consistió en el análisis comparativo del uso de tecnologías físicas y químicas frente al uso de las principales tecnologías de biorremediación para la depuración de aguas residuales (bioestimulación y bioaumentación). En esta fase, se utilizó también el supuesto basado en la frecuencia de citación de documentos científicos (índice Q). Las palabras clave en idioma inglés utilizadas durante esta fase de revisión fueron las siguientes: (i) wastewater (aguas residuales), (ii) bioremediation (biorremediación), (iii) physical (físico) y (iv) chemical (químico).

Se desarrolló una cuarta fase de revisión, con el objeto de analizar la distribución geográfica mundial del uso de la tecnología de biorremediación para la depuración de aguas residuales, mediante la base de datos Scopus y para la misma escala de tiempo de investigación. Se utilizó, también, el supuesto basado en la frecuencia de citación de documentos científicos para establecer un orden de importancia (índice Q) y se determinó la distribución porcentual por continente en relación al total de artículos detectados, a nivel mundial. Las palabras clave en idioma inglés utilizadas en esta fase de revisión fueron las siguientes: (i) wastewater (aguas residuales) y (ii) bioremediation (biorremediación).

El principal criterio de inclusión de la información bibliográfica seleccionada para la presente revisión fue que los documentos científicos reportaran datos cuantitativos de los factores clave identificados. De esta manera, en el análisis de cada factor clave, se consideró la siguiente cantidad de documentos científicos: (i) pH (35 documentos), (ii) temperatura (33), (iii) oxígeno (21), (iv) nitrógeno (27), (v) fósforo (21) y (vi) $\mathrm{DBO}_{5}$ (21); algunos documentos científicos se repitieron, debido a que incluyeron más de un factor clave. Finalmente, para la elaboración del presente manuscrito, se seleccionaron en total 51 documentos científicos.

Análisis estadístico. Las siguientes pruebas estadísticas fueron utilizadas para el análisis de datos durante la investigación bibliográfica. Inicialmente, se utilizó la prueba de Shapiro-Wilk, para contrastar la normalidad del conjunto de datos (variables). La prueba estadística $t$-Student, para muestras independientes, fue utilizada para analizar las diferencias entre las siguientes variables (Tabla 2): técnicas de biorremediación (bioaumentación, bioestimulación y fitorremediación), tipo de proceso (aerobio y anaerobio), $\mathrm{pH}$, temperatura, nitrógeno, tiempo de puesta en marcha del sistema y porcentaje de remoción de contaminantes (nitrógeno amoniacal, DQO, hidrocarburos, metales pesados, surfactante aniónico y DBO). También, se utilizó la prueba de Levene, para evaluar la igualdad de las varianzas del conjunto de datos. Finalmente, el coeficiente de correlación de Pearson fue utilizado para analizar la asociación lineal bilateral de las variables. Todas las pruebas estadísticas fueron calculadas para un nivel de confianza del $95 \%$.

\section{RESULTADOS Y DISCUSIÓN}

Análisis de factores clave en procesos de biorremediación. La tabla 1 presenta el índice de citación $(Q)$ y orden de importancia para los factores clave, identificados durante la presente investigación, después de aplicar la metodología propuesta. En el presente estudio, se observó que el orden de importancia para los factores clave en procesos de biorremediación para la depuración de aguas residuales, fue el siguiente: (i) $\mathrm{pH}(\mathrm{Q} 3=0,531)$; (ii) temperatura $(\mathrm{Q} 2=0,496)$; (iii) oxígeno $(\mathrm{Q} 2=0,457)$; (iv) nitrógeno $(\mathrm{Q} 2=0,421)$; (v) fósforo $(Q 1=0,240)$ y (vi) $\mathrm{DBO}_{5}(\mathrm{Q} 1=0,097)$. En este sentido, Margesin \& Schinner, (1998), Guo et al. (2010) y Sode et al. (2013) reportaron factores clave similares en procesos de biorremediación para la depuración de aguas residuales (DBO5, temperatura, pH, nitrógeno, fósforo y oxígeno). A continuación, se presentan los principales resultados para los seis factores clave, a partir del análisis bibliográfico de la información seleccionada.

$\mathrm{pH}$ (Índice $=0,531-\mathrm{Q3}$ ): Los resultados mostraron que este fue un factor clave, debido a que los microorganismos en procesos de biorremediación para la depuración de aguas residuales, requirieron un $\mathrm{pH}$ óptimo, como condición fundamental para su correcto desarrollo (Hassanshahian et al. 2013). Al respecto, Dibble et al. (1979) mencionaron que un $\mathrm{pH}>10$ inhibió el proceso de degradación bacteriana. Los resultados también mostraron que, en procesos de biorremediación para la depuración de aguas residuales, se mantuvieron pHs entre 4 y 9,1, con una mediana de 7,1 . La mediana fue utilizada como medida de tendencia central, debido a la existencia de valores extremos en la información presentada por la tabla 2. Por lo tanto, los hallazgos sugirieron que a pHs extremadamente ácidos o básicos, se pudieron inhibir los procesos de degradación bacteriana y, por lo tanto, reducir la eficiencia de remoción de contaminantes en los sistemas de biorremediación.

Temperatura (Índice $=0,496-Q 2$ ): Los resultados evidenciaron que este factor clave fue fundamental en el éxito del proceso de crecimiento bacteriano y, asimismo, en la desorción de contaminantes presentes en el agua residual a 


\begin{tabular}{|c|c|c|c|c|c|c|c|c|c|c|c|c|c|c|}
\hline 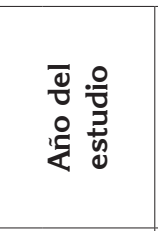 & 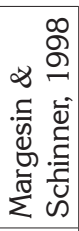 & 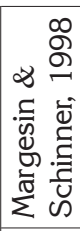 & 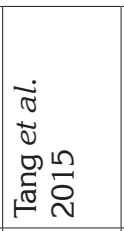 & 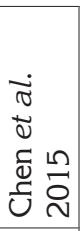 & 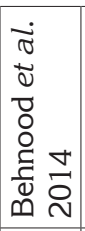 & 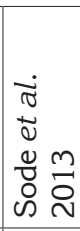 & 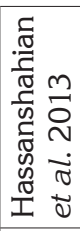 & 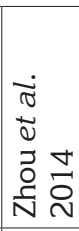 & 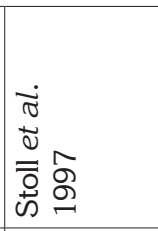 & 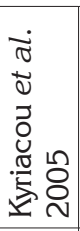 & 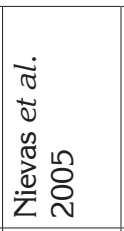 & 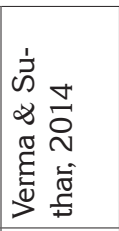 & 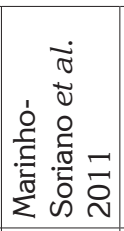 & 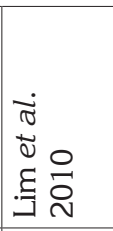 \\
\hline 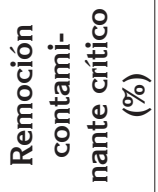 & 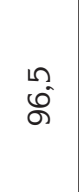 & $\begin{array}{l}\Omega \\
\infty \\
\infty\end{array}$ & $\begin{array}{l}\circ \\
\text { ஜ̆ }\end{array}$ & $\begin{array}{l}\infty \\
\infty \\
\sigma^{\circ}\end{array}$ & $\begin{array}{l}\circ \\
\stackrel{-}{\infty}\end{array}$ & $\begin{array}{l}* \\
\ddot{\sigma}\end{array}$ & $\begin{array}{l}0 \\
\stackrel{2}{N}\end{array}$ & ' & $\begin{array}{l}\circ \\
\infty \\
\infty\end{array}$ & $\begin{array}{l}0 \\
0 \\
0\end{array}$ & ๘ூ & $\stackrel{N}{\tilde{\theta}}$ & $\begin{array}{l}\text { டி } \\
\text { مे }\end{array}$ & 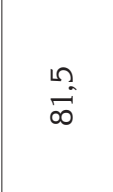 \\
\hline 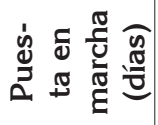 & $\begin{array}{l}\circ \\
\dot{\Xi}\end{array}$ & $\stackrel{\circ}{\sim}$ & $\stackrel{\circ}{\stackrel{+}{*}}$ & $\begin{array}{l}\circ \\
\stackrel{1}{n}\end{array}$ & $\begin{array}{l}\circ \\
\stackrel{1}{\sim}\end{array}$ & $\begin{array}{l}\circ \\
\infty \\
\infty\end{array}$ & $\begin{array}{l}\circ \\
1 \\
\end{array}$ & $\stackrel{0}{=}$ & ' & $\begin{array}{l}\circ \\
\text { m. }\end{array}$ & $\stackrel{0}{\circ}$ & $\begin{array}{l}\circ \\
\circ \\
\circ\end{array}$ & $\widetilde{N}$ & $\begin{array}{l}\circ \\
0\end{array}$ \\
\hline 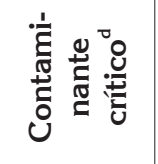 & \llcorner & $m$ & - & - & $m$ & - & $m$ & - & $\nabla$ & $\sim$ & $m$ & $\nabla$ & - & $\sim$ \\
\hline ㅇำ & ' & ' & ' & ' & ' & ' & $\begin{array}{l}0 \\
8 \\
8\end{array}$ & ' & ' & ' & ' & ' & ' & ' \\
\hline 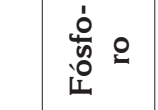 & $\begin{array}{l}\circ \\
\pm\end{array}$ & $\begin{array}{l}\circ \\
\pm \\
\pm\end{array}$ & ' & $\stackrel{\nabla}{\dot{m}}$ & ' & $\stackrel{m}{=}$ & ' & ' & ' & ' & ' & ' & $\widetilde{N}$ & $\stackrel{\circ}{\sim}$ \\
\hline 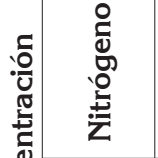 & $\begin{array}{l}0 \\
0^{\circ}\end{array}$ & $\begin{array}{l}0 \\
0^{\circ}\end{array}$ & $\begin{array}{l}\stackrel{\llcorner}{ } \\
\stackrel{\infty}{N}\end{array}$ & 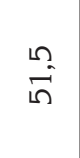 & ' & N & $\begin{array}{l}\circ \\
\text { O }\end{array}$ & $\begin{array}{l}\circ \\
\stackrel{\circ}{\circ}\end{array}$ & ' & ' & ' & ' & $\begin{array}{l}0 \\
\text { N }\end{array}$ & $\stackrel{\sim}{\sim}$ \\
\hline نํ. & ' & ' & ' & ' & ' & ' & I & ' & ' & ' & ' & ' & ח & $\stackrel{\llcorner}{\sim}$ \\
\hline 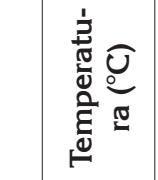 & $\stackrel{\circ}{\circ}$ & $\stackrel{\circ}{\circ}$ & $\vec{\sim}$ & ' & $\begin{array}{l}0 \\
\text { N }\end{array}$ & $\begin{array}{l}\circ \\
\stackrel{+}{\circ}\end{array}$ & $\begin{array}{l}\circ \\
\infty \\
\infty\end{array}$ & $\begin{array}{l}\circ \\
\stackrel{\sim}{N}\end{array}$ & & $\begin{array}{l}\circ \\
\stackrel{\leftrightarrow}{N}\end{array}$ & $\begin{array}{l}\circ \\
\stackrel{N}{N}\end{array}$ & $\begin{array}{l}\circ \\
\stackrel{0}{N}\end{array}$ & $\begin{array}{l}\text { N } \\
\text { Dे }\end{array}$ & $\begin{array}{l}\Omega \\
\mathscr{\varphi} \\
\dot{v}\end{array}$ \\
\hline$\frac{T}{2}$ & $\stackrel{\circ}{N}$ & $\stackrel{\circ}{N}$ & $\begin{array}{l}\infty \\
\sigma^{-}\end{array}$ & $\stackrel{\infty}{N}$ & $\stackrel{\sim}{\forall}$ & $\begin{array}{l}+ \\
\infty\end{array}$ & $\stackrel{\circ}{N}$ & $\begin{array}{l}\circ \\
\infty\end{array}$ & $\stackrel{m}{n}$ & $\stackrel{\Omega}{\forall}$ & $\stackrel{\infty}{N}$ & $\stackrel{\circ}{N}$ & $\underset{\infty}{\sim}$ & $\stackrel{0}{N}$ \\
\hline 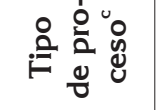 & - & - & - & - & - & $\sim$ & - & $\sim$ & - & - & ' & ' & - & - \\
\hline 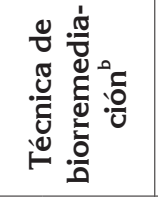 & - & - & - & - & - & $m$ & $\neg$ & $\sim$ & $\sim$ & - & $\sim$ & $\sim$ & $m$ & $m$ \\
\hline 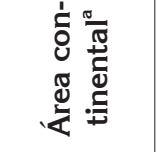 & - & - & $N$ & $m$ & $m$ & - & $m$ & $m$ & $\nabla$ & - & เ & $m$ & م & $m$ \\
\hline : & 量 & 量 & 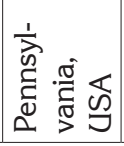 & 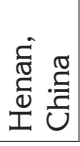 & .్ర్ల్ర & 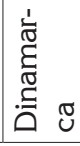 & 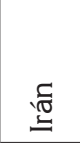 & 客 & 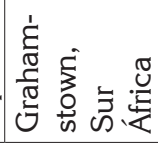 & 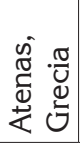 & 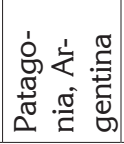 & 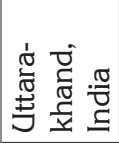 & 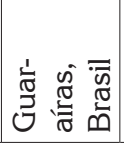 & 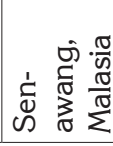 \\
\hline
\end{tabular}




\begin{tabular}{|c|c|c|c|c|c|c|c|c|c|c|c|c|c|c|c|c|}
\hline 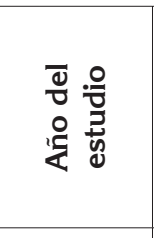 & 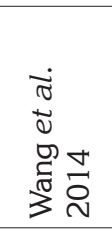 & 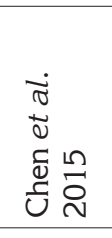 & 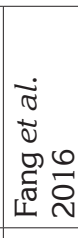 & $\begin{array}{l}\dot{\sigma} \\
\widetilde{\Xi} \\
\stackrel{0}{0} \\
\stackrel{0}{0}\end{array}$ & 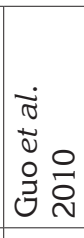 & $\begin{array}{l}\vec{\sigma} \\
\widetilde{v} \\
\stackrel{0}{\partial} \\
\stackrel{0}{0}\end{array}$ & 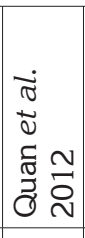 & 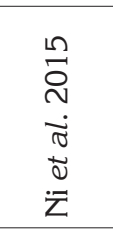 & 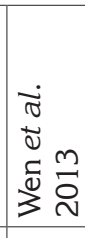 & 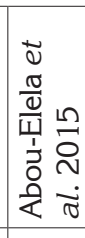 & 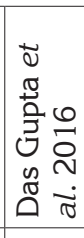 & 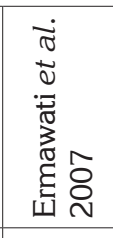 & 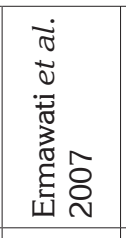 & 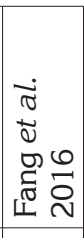 & $\begin{array}{l}\vec{\Xi} \\
\bar{N} \\
\dot{\sigma} \\
\overrightarrow{0} \\
:\end{array}$ & 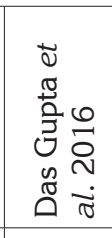 \\
\hline 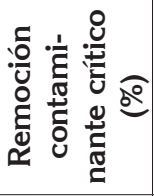 & $\hat{n}$ & $\begin{array}{l}\text { के } \\
\text { ه̊ }\end{array}$ & $\begin{array}{l}0 \\
\infty^{\circ}\end{array}$ & $\stackrel{\sim}{\infty}$ & స్ & $\begin{array}{l}\text { वे } \\
\text { से }\end{array}$ & ஜ̊ & $\begin{array}{l}\stackrel{0}{\infty} \\
\infty\end{array}$ & $\begin{array}{l}\stackrel{0}{\infty} \\
\infty\end{array}$ & 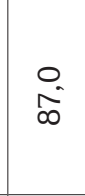 & ஜి & : & $\begin{array}{l}0 \\
\stackrel{0}{\circ}\end{array}$ & $\hat{\text { ถ் }}$ & $\stackrel{0}{\stackrel{0}{\infty}}$ & $\frac{m}{\sigma}$ \\
\hline 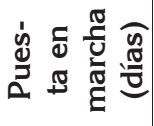 & $\stackrel{\circ}{N}$ & $\tilde{F}$ & $\stackrel{n}{=}$ & $\begin{array}{l}\text { ñ } \\
\overbrace{}^{\prime}\end{array}$ & $\hat{0}$ & $\stackrel{\nabla}{\circ}$ & $\stackrel{\circ}{m}$ & $\begin{array}{l}0 \\
\stackrel{\infty}{N}\end{array}$ & $\begin{array}{l}0 \\
\stackrel{1}{n}\end{array}$ & $\overrightarrow{0}$ & $\begin{array}{l}\circ \\
0\end{array}$ & $\stackrel{\circ}{\stackrel{\circ}{\Omega}}$ & $\begin{array}{l}\circ \\
\stackrel{9}{\sim}\end{array}$ & $\begin{array}{l}0 \\
0 \\
0\end{array}$ & $\begin{array}{l}0 \\
\dot{q}\end{array}$ & $\begin{array}{l}\circ \\
\dot{m}\end{array}$ \\
\hline 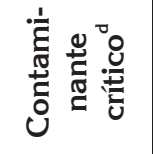 & $\sim$ & $\sim$ & $N$ & $\sim$ & $\sim$ & $\sim$ & $N$ & $\sim$ & $\sim$ & $\sim$ & 0 & 0 & 0 & 0 & $\sim$ & $\sim$ \\
\hline $\begin{array}{l}\text { ㅇ } \\
\text { 口̆ }\end{array}$ & ' & ' & $\overrightarrow{\mathrm{N}}$ & $\begin{array}{l}\stackrel{0}{8} \\
\stackrel{0}{(1}\end{array}$ & $\stackrel{\circ}{\stackrel{\circ}{N}}$ & 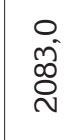 & . & ' & ' & $\begin{array}{l}\text { मे } \\
\text { d. }\end{array}$ & $\begin{array}{l}0 \\
\text { \& }\end{array}$ & $\begin{array}{l}0 \\
\stackrel{0}{8} \\
\infty\end{array}$ & $\begin{array}{l}0 \\
8 \\
\stackrel{8}{0} \\
\stackrel{1}{N}\end{array}$ & $\stackrel{\circ}{\stackrel{\omega}{N}}$ & ' & $\begin{array}{l}0 \\
\prod_{\infty}^{-} \\
\infty\end{array}$ \\
\hline 定。 & $\stackrel{n}{\sim}$ & 오 & ' & ' & ' & ' & $\begin{array}{l}\circ \\
\stackrel{\text { ñ }}{=}\end{array}$ & ' & $\stackrel{\llcorner}{N}$ & ' & $\begin{array}{l}\text { O } \\
\text { ᄋ }\end{array}$ & ' & ' & $\begin{array}{l}0 \\
\sigma^{\prime}\end{array}$ & $\stackrel{\circ}{\circ}$ & $\stackrel{n}{\sim}$ \\
\hline 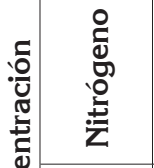 & $\stackrel{\sim}{\infty} \underset{\sim}{\sim}$ & $\begin{array}{l}\text { : } \\
\text { in }\end{array}$ & $\frac{N}{n}$ & $\stackrel{0}{r}$ & $\stackrel{\text { a }}{\sim}$ & $\stackrel{\nabla}{i}$ & : & ' & $\begin{array}{l}0 \\
\text { O̊ } \\
\text { in }\end{array}$ & $\stackrel{\circ}{+}$ & ' & ' & ' & $\begin{array}{l}0 \\
\theta_{0}^{\prime}\end{array}$ & $\stackrel{0}{\text { i }}$ & \\
\hline ن̋ & g. & $\stackrel{0}{-}$ & $\stackrel{0}{-}$ & $\stackrel{\circ}{-}$ & $\stackrel{0}{-}$ & $\stackrel{\circ}{-}$ & $\stackrel{\circ}{i}$ & $\stackrel{\circ}{-}$ & 1 & $\stackrel{\circ}{\rightarrow}$ & $\infty^{\circ}$ & $\stackrel{\circ}{\forall}$ & ' & ' & ㅇ. & ' \\
\hline 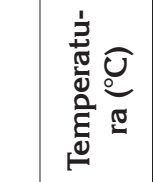 & $\stackrel{\infty}{\vec{N}}$ & $\begin{array}{l}\text { : } \\
\text { in }\end{array}$ & ' & 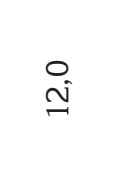 & $\stackrel{0}{\stackrel{\rho}{\sim}}$ & $\stackrel{0}{\stackrel{0}{\sim}}$ & $\stackrel{\circ}{\stackrel{\sim}{+}}$ & $\begin{array}{l}0 \\
\stackrel{N}{N}\end{array}$ & ' & $\begin{array}{l}0 \\
\stackrel{\infty}{N}\end{array}$ & ' & $\begin{array}{l}0 \\
\dot{n}\end{array}$ & $\begin{array}{l}0 \\
\text { ì }\end{array}$ & ' & $\stackrel{\llcorner}{\tilde{N}}$ & $\stackrel{\llcorner}{m^{n}}$ \\
\hline T & $\stackrel{N}{N}$ & Oे & $\vec{N}$ & ' & ' & ' & 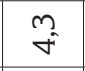 & $\stackrel{0}{i}$ & $\vec{\sigma}$ & ' & $\begin{array}{l}\stackrel{N}{\infty} \\
\infty\end{array}$ & $\stackrel{\Omega}{N}$ & $\vec{N}$ & ' & $\stackrel{\circ}{N^{\prime}}$ & $\stackrel{\circ}{\circ}$ \\
\hline 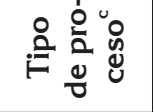 & $\neg$ & $\neg$ & - & - & - & - & - & - & - & $\tau$ & $\tau$ & - & $\sim$ & ' & $\sim$ & - \\
\hline 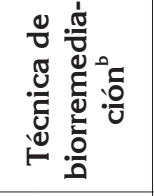 & $m$ & - & - & - & - & - & - & - & - & $\sim$ & $\sim$ & - & - & $\sim$ & $\sim$ & $\sim$ \\
\hline 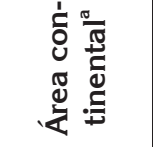 & $m$ & $m$ & $m$ & $m$ & $m$ & $m$ & $m$ & $m$ & $m$ & $\nabla$ & $m$ & $m$ & $m$ & $m$ & $m$ & $m$ \\
\hline 苞 & 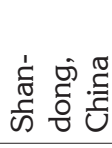 & 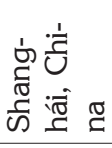 & : & 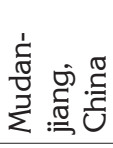 & 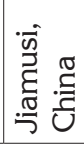 & 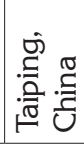 & 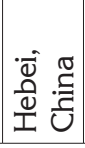 & 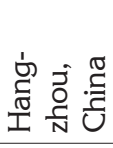 & 节 & 过 : & 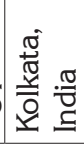 & 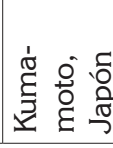 & 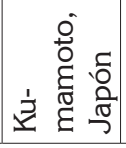 & 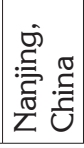 & : & 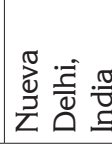 \\
\hline
\end{tabular}




\begin{tabular}{|c|c|c|c|c|c|c|c|c|c|c|c|c|c|c|c|c|c|}
\hline 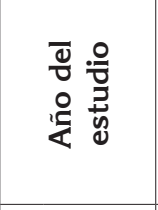 & 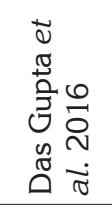 & 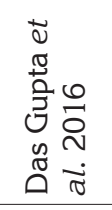 & 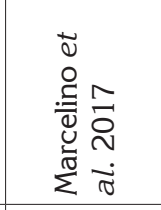 & 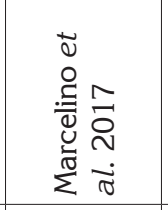 & 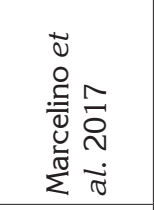 & 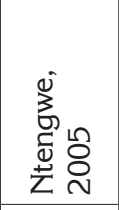 & 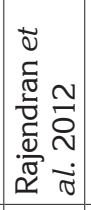 & 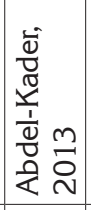 & 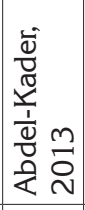 & 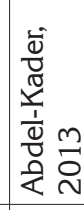 & & & & & & & 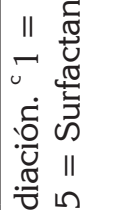 \\
\hline 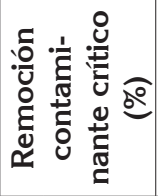 & $\widetilde{\infty}$ & 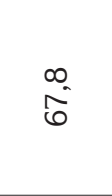 & $\begin{array}{l}0 \\
\dot{\varphi}\end{array}$ & @ & $\begin{array}{l}0 \\
\infty \\
\infty\end{array}$ & $\begin{array}{l}0 \\
\varnothing \\
\infty\end{array}$ & $\begin{array}{l}0 \\
\text { ⿵े }\end{array}$ & $\overrightarrow{\text { ले }}$ & & $\begin{array}{l}0 \\
\stackrel{\circ}{ }\end{array}$ & $\begin{array}{r}\hat{N} \\
\infty \\
\infty\end{array}$ & \& & $\mid \begin{array}{c}m \\
\infty \\
-\infty\end{array}$ & \begin{tabular}{l}
\multirow{\bullet}{*}{} \\
$\stackrel{0}{*}$
\end{tabular} & $\begin{array}{l}\infty \\
\infty \\
\infty\end{array}$ & ले & 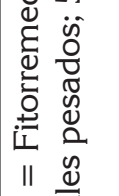 \\
\hline 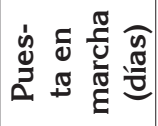 & $\stackrel{\circ}{\text { m }}$ & $\stackrel{\circ}{\text { m }}$ & $\stackrel{0}{\circ}$ & $\stackrel{0}{\circ}$ & $\stackrel{0}{0}$ & $\stackrel{\circ}{\dot{m}}$ & $\stackrel{\circ}{-}$ & ' & ' & ' & $\begin{array}{l}0 \\
\infty\end{array}$ & 0 & $\begin{array}{l}\infty \\
\infty \\
\infty\end{array}$ & $\overline{0}$ & $\begin{array}{l}0 \\
\vdots \\
\dot{q}\end{array}$ & $\stackrel{m}{m}$ & 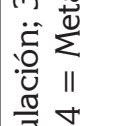 \\
\hline 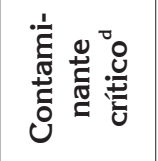 & $\sim$ & $\sim$ & 0 & 0 & 0 & 0 & 0 & 0 & 0 & 0 & & & & & & & 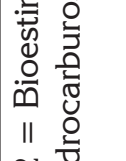 \\
\hline 옴 & $\stackrel{\circ}{m}$ & $\begin{array}{l}0 \\
\stackrel{8}{8} \\
\text { m }\end{array}$ & $\begin{array}{l}\text { mे } \\
\text { ồ }\end{array}$ & $\begin{array}{l}\text { : } \\
\text { Nं }\end{array}$ & $\begin{array}{l}0 \\
\ddot{\theta}\end{array}$ & $\begin{array}{l}\circ \\
\infty^{0}\end{array}$ & $\begin{array}{l}0 \\
\hat{0} \\
\mathbb{W} \\
m\end{array}$ & 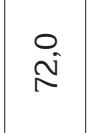 & $\stackrel{0}{\Xi}$ & $\begin{array}{c}0 \\
\stackrel{0}{0} \\
\stackrel{\infty}{\sim}\end{array}$ & $\begin{array}{l}\text { a } \\
- \\
\text { D } \\
\text { i }\end{array}$ & $\begin{array}{l}\text { O } \\
\text { N } \\
m\end{array}$ & 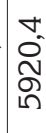 & $\begin{array}{l}0 \\
\infty^{\infty} \\
\text { o }\end{array}$ & 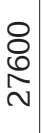 & $\vec{N}$ & 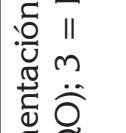 \\
\hline$\frac{\dot{0}}{n} 0$ & $\stackrel{n}{\sim}$ & $\stackrel{n}{\sim}$ & ' & ' & ' & $\ddot{0}$ & $\Rightarrow$ & $\hat{m}$ & $\begin{array}{l}\infty \\
\sigma\end{array}$ & $\begin{array}{l}0 \\
\underset{ \pm}{-}\end{array}$ & 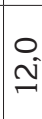 & $\begin{array}{l}0 \\
0\end{array}$ & 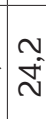 & 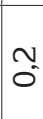 & $\begin{array}{l}0 \\
\stackrel{0}{=}\end{array}$ & $\vec{N}$ & 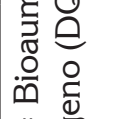 \\
\hline 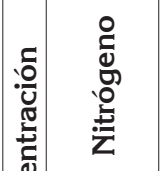 & $\stackrel{N}{\Rightarrow}$ & $\stackrel{\stackrel{\sim}{N}}{\stackrel{N}{*}}$ & ' & ' & ' & $\ddot{\circ}$ & $\begin{array}{l}0 \\
\infty^{\circ} \\
n^{\circ}\end{array}$ & $\stackrel{\circ}{i}$ & $\begin{array}{l}0 \\
\infty\end{array}$ & $\stackrel{\circ}{\stackrel{M}{\sim}}$ & $\begin{array}{l}m \\
10 \\
0\end{array}$ & i & $\stackrel{+}{\stackrel{+}{ \pm}}$ & $\ddot{0}$ & $\begin{array}{l}0 \\
8 \\
8\end{array}$ & $\hat{N}$ & 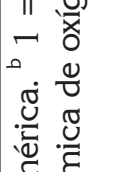 \\
\hline ن & ' & ' & $\stackrel{m}{\sim}$ & $\stackrel{\sim}{\sim}$ & 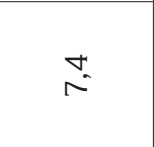 & $\stackrel{0}{-}$ & ' & $\mathfrak{O}_{0}^{N}$ & $\mathfrak{O}_{0}^{N}$ & $\overbrace{0}^{N}$ & ò & $\stackrel{0}{-}$ & $\begin{array}{l}0 \\
\text { i }\end{array}$ & $\widetilde{N}$ & $\begin{array}{l}0 \\
\infty\end{array}$ & $\vec{N}$ & 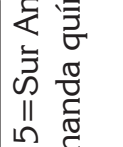 \\
\hline 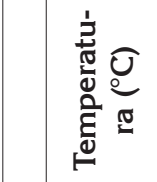 & $\stackrel{\sim}{\tilde{m}^{m}}$ & $\stackrel{n}{\tilde{m}^{n}}$ & م્ & 오 & 오 & $\stackrel{n}{\text { N }}$ & ' & $\begin{array}{l}\text { i } \\
\text { N }\end{array}$ & 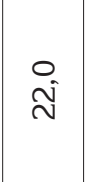 & $\begin{array}{l}\stackrel{0}{\mathrm{~N}} \\
\text { }\end{array}$ & $\stackrel{m}{\stackrel{n}{N}}$ & 옹 & 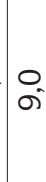 & $\stackrel{\circ}{\circ}$ & 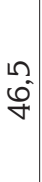 & $\stackrel{m}{m}$ & 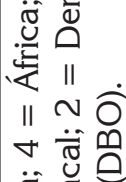 \\
\hline$\frac{I}{2}$ & $\stackrel{\circ}{\circ}$ & $\begin{array}{l}\circ \\
\forall\end{array}$ & $\stackrel{\circ}{N}$ & ㅇ. & $\stackrel{\operatorname{Ln}}{\sim}$ & $\stackrel{n}{\sim}$ & $\stackrel{m}{N}$ & o. & $\vec{N}$ & $\stackrel{⿱}{N}$ & $\begin{array}{l}0 \\
0\end{array}$ & 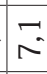 & $\stackrel{F}{=}$ & $\stackrel{\circ}{\rightarrow}$ & $\vec{\sigma}$ & $\stackrel{n}{m}$ & \\
\hline 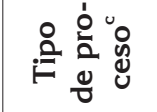 & - & - & - & - & - & - & - & - & - & - & & & & & & & 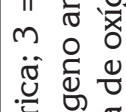 \\
\hline 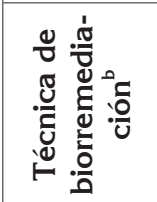 & $\sim$ & $\sim$ & $\sim$ & $\sim$ & $\sim$ & $N$ & - & $N$ & $N$ & $N$ & & & & & & & 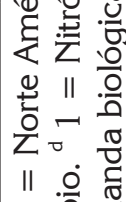 \\
\hline 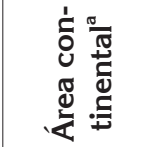 & $m$ & $m$ & ח & ח & ח & $\nabla$ & - & $m$ & $m$ & $m$ & & & 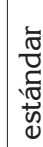 & & & 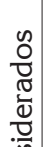 & 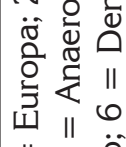 \\
\hline סू & 离 & 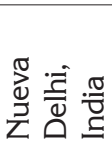 & 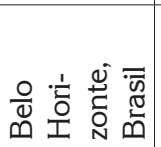 & 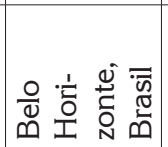 & 임 & 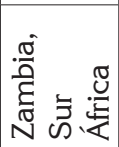 & 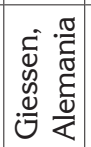 & 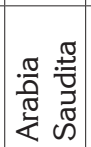 & 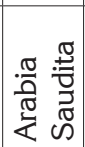 & 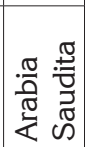 & $\frac{\pi}{\pi}$ & 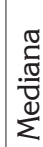 & 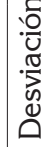 & 总 & 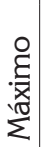 & $\begin{array}{l}0 \\
0 \\
0 \\
0 \\
0 \\
0 \\
0 \\
0\end{array}$ & 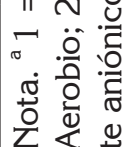 \\
\hline
\end{tabular}


depurar (Abou-Elela et al. 2015). Condiciones extremas o fluctuaciones de temperatura impidieron el desarrollo de los consorcios bacterianos y su control mejoró la eficiencia en la biodegradabilidad y capacidad de mineralización en sistemas de depuración para agua residual (Tyagi et al. 2011; Rana et al. 2017). La presente investigación, también mostró que, en procesos de biorremediación para la depuración de aguas residuales, se mantuvieron temperaturas entre 4 y $46,5^{\circ} \mathrm{C}$, con una mediana de $25^{\circ} \mathrm{C}$ (Tabla 2). Los resultados sugirieron una amplia fluctuación en los valores de temperatura en sistemas de biorremediación para la depuración de aguas residuales, probablemente, debido al tipo de microorganismos utilizados. Se detectó el uso de microorganismos que se desarrollaron a bajas (psicrófilos) y altas temperaturas (termófilos). Guo et al. (2010) reportaron resultados similares en sistemas de biorremediación para la depuración de aguas residuales.

Oxígeno (Índice $=0,457-Q 2$ ): La investigación mostró que la presencia de oxígeno disuelto en el agua residual en procesos de biorremediación aeróbicos fue un factor determinante en la reducción de contaminantes, como $\mathrm{DBO}_{5}, \mathrm{DQO}$, grasas y aceites, sólidos disueltos totales (SDT) y sólidos suspendidos totales (SST) (Gao et al. 2013). Los resultados también mostraron que en procesos de biorremediación para la depuración de aguas residuales, se mantuvieron concentraciones de oxígeno entre 0,2 y 8ppm, con una mediana de 2,85ppm (Tabla 2). Los resultados sugirieron un amplio rango en la concentración de oxígeno disuelto en sistemas de depuración de agua residual, debido, probablemente, a que en la presente investigación bibliográfica se consideraron sistemas aerobios y anaerobios de biorremediación.

Adicionalmente, los resultados mostraron que el oxígeno fue un elemento vital para las bacterias aerobias, de encontrase en las cantidades correctas o en exceso, contribuyó al desarrollo microbiológico, pero si se encontró de manera deficitaria generó competencia microbiana. Lo anterior evidenció una reducción en la cantidad de microorganismos y, a su vez, causó una reducción de la eficiencia en la biodegradabilidad de los contaminantes presentes en el agua residual (Tyagi et al. 2011; Marinho-Soriano et al. 2011).

Nitrógeno (Índice $=0,421-\mathrm{Q} 2$ ): Los resultados mostraron que este fue el macronutriente de mayor importancia en procesos de biorremediación para la depuración de aguas residuales; frecuentemente, este nutriente requirió ser añadido para acelerar la velocidad de descontaminación, debido al mejoramiento del potencial de degradación bacteriano (Margesin \& Schinner, 1998; Nikolopoulou et al. 2009). La presente investigación, también mostró que, en procesos de biorremediación para la depuración de aguas residuales, se mantuvo una concentración de nitrógeno entre 0,4 y 600ppm, con una mediana de 20ppm (Tabla 2). Los re- sultados sugirieron que este amplio rango de variación en la concentración de nitrógeno, probablemente, estuvo asociado con la cantidad de DBO a eliminar en los sistemas de tratamiento, es decir, en las depuradoras, se debieron mantener relaciones de $\mathrm{DBO}_{5} / \mathrm{N}$, entre $100 / 1$ y $100 / 5$, para garantizar los procesos de crecimiento bacteriano y desorción de contaminantes (Nannipieri et al. 2003), lo cual, probablemente, generó una amplia variación en la concentración de nitrógeno dosificada y reportada por las investigaciones seleccionadas.

Fósforo (Índice $=0,240-Q 1$ ): Los resultados evidenciaron que este factor clave fue el segundo macronutriente de mayor importancia en la biorremediación de contaminantes en aguas residuales, que requirió ser añadido, para garantizar el desarrollo microbiológico (Sarkar et al. 2005; Nikolopoulou et al. 2009). La presente investigación mostró que, en procesos de biorremediación para la depuración de aguas residuales, se mantuvo una concentración de fósforo, entre 0,2 y $115 p p m$, con una mediana de 20ppm (Tabla 2). Los resultados sugirieron que este amplio rango de variación en la concentración de fósforo, probablemente, estuvo asociado con la cantidad de DBO a eliminar en los sistemas de tratamiento, es decir, en las depuradoras, se debieron mantener relaciones de DBO5/P, entre 100/0,5 y 100/1 (Nannipieri et al. 2003), lo cual, probablemente, generó una amplia variación en la concentración de fósforo dosificada y reportada por las investigaciones.

$\underline{\mathrm{DBO}}_{5}$ (Índice $=0,097-\mathrm{Q1}$ ): Los resultados evidenciaron que este factor clave fue considerado como un contaminante del agua (Osuolale et al. 2015), pero también fue reportado como una fuente significativa de suministro de carbono, para procesos metabólicos bacterianos, en sistemas de biorremediación, para la depuración del agua residual (Liu et al. 1996; Kahmark \& Unwin, 1998; Kumar et al. 2010). Los resultados, también mostraron que en procesos de biorremediación, se mantuvo una concentración de $\mathrm{DBO}_{5}$, entre 48 y 27600ppm, con una mediana de 2092ppm (Tabla 2). Esta amplia variación en la concentración de $\mathrm{DBO}_{5}$, probablemente, fue debida a que se seleccionaron artículos científicos donde se reportaron diferentes tipos de agua residual (doméstica e industrial) y con variados grados de contaminación.

Finalmente, en la tabla 1 (fase 3), se evidenció que las tecnologías químicas para la depuración de aguas residuales tuvieron la mayor frecuencia de citación $(Q 2=0,457)$, seguida por las tecnologías físicas ( $Q 2=0,270$ ) y de biorremediación $(Q 1=0,026)$. A partir de lo anterior, los resultados sugirieron que las tecnologías de biorremediación durante el periodo de estudio (entre los años 1997 y 2016) fueron, probablemente, las de menor uso o que se encontraron en una fase inicial de desarrollo y de aplicación en sistemas de depuración de aguas residuales, a nivel mundial. 
Relación entre factores clave en procesos de biorremediación.

Relación C/N/P: Los resultados mostraron que, en procesos de biorremediación aerobios, se utilizó una relación de carbono y nutrientes (DBO5/N/P), entre 100/1/0,5 y 100/5/1 (Nannipieri et al. 2003). Adicionalmente, en técnicas de bioestimulación y bioaumentación, se utilizaron fertilizantes comerciales con contenido de $\mathrm{N}$ y P, para garantizar el óptimo nutricional del proceso metabólico bacteriano (Duke et al. 2000; García et al. 2007; Sanscartier et al. 2009). Los resultados en la tabla 2 permitieron evidenciar la existencia de una correlación lineal directa entre $\mathrm{N}$ y P $(r$-Pearson $=0,688$; p-valor = 0,001; gl. = 19). Se desarrolló el siguiente modelo de regresión lineal entre estas variables: $N=4,70 * P+1,20$. En promedio, a nivel mundial, la investigación bibliográfica sugirió una relación N/P, de 4,70 en procesos de biorremediación para la depuración de aguas residuales.

Factores clave: Los análisis estadísticos aplicados a la información presentada en la tabla 2 permitieron evidenciar la no existencia de diferencias significativas entre las técnicas de bioaumentación y bioestimulación, en relación a los siguientes factores clave: $\mathrm{pH}(t$-Student $=0,548$; $\mathrm{p}$-valor $=0,588$; gl. = 29); oxígeno ( $t$-Student $=-2,107$; p-valor $=0,058$; gl. = 16); nitrógeno ( $t$-Student $=1,669$; p-valor $=0,12$; gl. $=$ 21 ); tiempo de puesta en marcha ( $t$-Student $=0,571$; $\mathrm{p}$-valor $=0,573$; gl. $=30)$; porcentaje de remoción $(t$-Student $=-0,342$; p-valor $=0,735$; gl. $=34)$ y $\mathrm{DBO}_{5}(t-$ Student $=$ 1,639; p-valor = 0,118; gl. = 19). Por lo tanto, los resultados sugirieron que los factores clave fueron similares para las dos tecnologías de biorremediación en estudio. De esta manera, en las tecnologías de bioaumentación y bioestimulación, se debieron garantizar los mismos factores clave, para la desorción eficiente de los contaminantes, presentes en el agua residual a depurar.

pH y P: La revisión bibliográfica permitió observar una relación inversa entre $\mathrm{pH}$ y fósforo $(r$-Pearson $=-0,410$; $\mathrm{p}$-valor $=0,036$; gl. $=20$ ), la cual, probablemente, pudo estar asociada al uso de ácidos con contenido de fósforo, como nutrientes en los procesos de biorremediación (Tabla 2), es decir, a mayor contenido de fósforo menor fue el $\mathrm{pH}$ en el sistema de biorremediación. Adicionalmente, Hong et al. (2009) indicaron que, en el ciclo del fosfato en aguas residuales, predominó la fracción de ácido fosfórico y el ion dihidrogenofosfato ( $\mathrm{pH}<6$ ), lo cual, también sustentó la relación inversa entre $\mathrm{pH}$ y fósforo, reportada por las investigaciones en sistemas de biorremediación.

Temperatura y porcentaje de remoción: La investigación bibliográfica mostró la probable existencia de una relación directa entre temperatura y porcentaje de remoción de contaminantes en sistemas de biorremediación $(r$-Pearson $=$
-0,385; p-valor = 0,030; gl. = 32), sugiriendo que, a mayor temperatura, posiblemente, existió un mayor porcentaje de remoción de contaminantes (Tabla 2). Esto, probablemente, se debió a que fue necesario mantener en sistemas de depuración de aguas residuales condiciones óptimas para bacterias mesófilas y termófilas. Los resultados, quizás, también sugirieron que, en sistemas de biorremediación, se tendió a operar bajo condiciones de elevada temperatura, para obtener una mayor degradación de los contaminantes, presentes en el agua residual. Tyagi et al. (2011) y Rana et al. (2017) han reportado una tendencia similar en sistemas de depuración.

DBO $_{5}$ y puesta en marcha: Los análisis estadísticos aplicados a la información presentada en la tabla 2 permitieron observar una relación directa entre $\mathrm{DBO}_{5}$ y tiempo de puesta en marcha $(r$-Pearson $=0,552$; p-valor $=0,018$; gl. $=18)$. Los resultados sugirieron que, a mayores concentraciones de materia orgánica, seguramente, se requirió un mayor tiempo de puesta en marcha para los sistemas de biorremediación de aguas residuales. Igualmente, Castillo et al. (2011) indicaron que, a mayor porcentaje de remoción de $\mathrm{DBO}_{5}$, mayor fue el tiempo requerido para la puesta en marcha del sistema de biorremediación.

Análisis geográfico a nivel mundial. Se realizó un análisis geográfico mundial del uso de técnicas de biorremediación, a partir de la información detectada por la base de datos Scopus (Tablas 1 y 2). Los resultados mostraron el siguiente orden de importancia en el uso de sistemas de biorremediación, a nivel mundial: Asia (41,3\%), Europa (28,8\%), América del Norte (20,1\%), América del Sur (3,3\%), Oceanía (3,3\%) y África (3,2\%). De esta manera, el continente asiático demostró ser el de mayor impacto en el uso de sistemas de biorremediación para la depuración de aguas residuales. Al respecto, Chen et al. (2015) y Tang et al. (2015) reportaron el establecimiento de nuevas plantas y la modernización de plantas antiguas de depuración, mediante el uso de tecnologías de biorremediación, en China.

El análisis geográfico, también permitió detectar la distribución con relación al uso mundial de las tecnologías de biorremediación (Tabla 2). Los resultados mostraron el siguiente orden de importancia, mundialmente: bioaumentación (45\%), bioestimulación (45\%) y fitorremediación (10\%). Por lo tanto, los resultados sugirieron una frecuencia de uso similar, a nivel mundial, de las tecnologías de bioaumentación y bioestimulación para la depuración de aguas residuales; no obstante, en Asía, Europa y Norte América predominó la tecnología de bioaumentación y en Sur América y África imperó la tecnología de bioestimulación; por ejemplo, Guo et al. (2010) indicaron que en China existió una marcada tendencia en el uso de la tecnología de bioaumentación, debido a que permitió incorporar bacterias especializadas, 
para la eliminación de contaminantes específicos, en aguas residuales domésticas (Gong, 2012).

Adicionalmente, se analizó el uso en el tiempo de sistemas de biorremediación para la depuración de aguas residuales, a nivel mundial. Los resultados mostraron que, durante el período comprendido entre 1997 y 2010, se detectaron el $30,5 \%$ de los casos (Figura 1). Durante este período, la bioaumentación representó un $63 \%$ y la bioestimulación un 27\%. Posteriormente, durante el periodo comprendido entre 2010 y 2016 existió un incremento en el uso de sistemas de biorremediación. En este lapso, se detectaron el 69,5\% de los casos, de los cuales, la bioestimulación representó el $60 \%$ y la bioaumentación el $40 \%$. La tasa de crecimiento en el uso de tecnologías de bioestimulación y bioaumentación, a nivel mundial, fue de 0,163 casos/año y 0,169 casos/año, respectivamente. En el presente estudio, los resultados sugirieron que, a nivel mundial, no existieron diferencias en el uso de las tecnologías de bioestimulación y bioaumentación para la depuración de aguas residuales, durante el periodo comprendido entre 1997 y 2016.

En conclusión, la presente investigación sugiere, en orden de importancia, la existencia de seis factores clave en procesos de biorremediación para la depuración de aguas residuales: $\mathrm{pH}>$ temperatura $>$ oxígeno $>$ nitrógeno $>$ fósforo $>$ $\mathrm{DBO}_{5}$. Al respecto, se observan tres grupos para los factores clave, según su frecuencia de citación: (Q3) pH; (Q2) temperatura, oxígeno y nitrógeno y (Q1) fósforo y $\mathrm{DBO}_{5}$. Los resultados sugieren que no existen diferencias significativas entre las tecnologías de bioaumentación y biorremediación en relación a los seis factores clave identificados. Igualmente, no se evidencia, a nivel mundial, una tendencia en el uso de alguna de las dos tecnologías; sin embargo, en Asia, Europa y Norte América existe mayor reporte en el uso de la tecnología de bioaumentación y en Sur América y África, mayor reporte de la tecnología de bioestimulación. Se evidencia, durante el período de investigación, que las tecnologías de biorremediación (Q1), probablemente, se encuentran aún en una fase inicial de desarrollo y de aplicación en sistemas de depuración para aguas residuales. En orden de importancia las tecnologías químicas (Q2) y físicas (Q2) presentan un mayor reporte, a nivel mundial.

Finalmente, los resultados de la presente investigación permiten profundizar el conocimiento acerca de la utilización de tecnologías de biorremediación para la depuración de aguas residuales y son un punto de referencia para las instituciones ambientales, encargadas del control de la calidad del agua y diseñadores y operadores de sistemas de depuración.

Agradecimientos: Los autores agradecen a los grupos de investigación para el Desarrollo Sostenible (INDESOS) e Ingeniería Ambiental (GIIAUD) de la Universidad Distrital Francisco José de Caldas (Colombia). Conflictos de intereses: El manuscrito fue preparado y revisado con la participación de todos los autores, quienes declaramos que no existe conflicto de intereses que ponga en riesgo la validez de los resultados presentados.

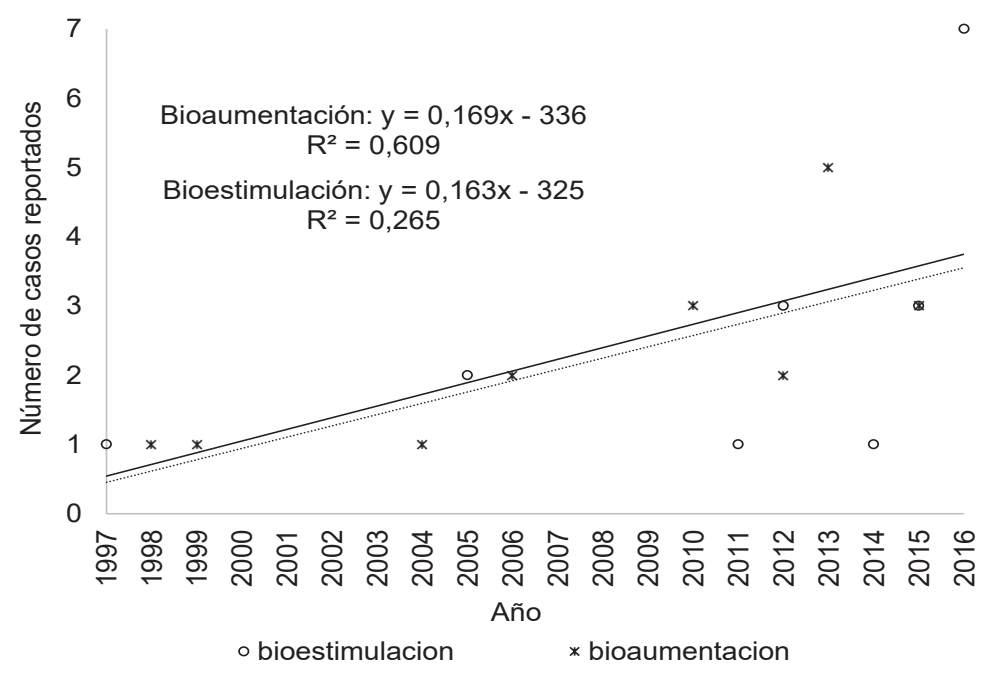

Figura 1. Análisis temporal del uso de técnicas de biorremediación, a nivel mundial: bioestimulación y bioaumentación ( $\mathrm{n}=36$ casos). 


\section{REFERENCIAS}

1. ABDEL-KADER, A.M. 2013. Studying the efficiency of grey water treatment by using rotating biological contactors system. J. King. Saud. Univ. Eng. Sci. 25(2):8995. https://doi.org/10.1016/j.jksues.2012.05.003

2. ABOU-ELELA, S.I.; FAWZY, M.E.; EL-GENDY, A.S. 2015. Potential of using biological aerated filter as a post treatment for municipal wastewater. Ecol. Eng. 84:5357. https://doi.org/10.1016/j.ecoleng.2015.07.022

3. BEHNOOD, M.; NASERNEJAD, B.; NIKAZAR, M. 2014. Biodegradation of crude oil from saline waste water using white rot fungus Phanerochaete chrysosporium. J. Ind. Eng. Chem. 20(4):1879-1885. https://doi. org/10.1016/j.jiec.2013.09.007

4. CASTILLO, E.; LIZAMA, C.; MÉNDEZ, R.; GARCÍA, J.; ESPADAS, A.; PAT, R. 2011. Tratamiento de efluentes de fosas sépticas por el proceso de lodos activados. Ingeniería. 15(3):529-565.

5. CHEN, Q.; NI, J.; MA, T.; LIU, T.; ZHENG, M. 2015. Bioaugmentation treatment of municipal wastewater with heterotrophic-aerobic nitrogen removal bacteria in a pilot-scale SBR. Bioresour. Technol. 183:25-32. https://doi.org/10.1016/j.biortech.2015.02.022

6. DANALEWICH, J.R.; PAPAGIANNIS, T.G.; BELYEA, R.L.; TUMBLESON, M.E.; RASKIN, L. 1998. Characterization of dairy waste streams, current treatment practices, and potential for biological nutrient removal. Water Res. 32(12):3555-3568. https://doi. org/10.1016/S0043-1354(98)00160-2

7. DAS GUPTA, A.; SARKAR, S.; GHOSH, P.; SAHA, T.; SIL, A.K. 2016. Phosphorous dynamics of the aquatic system constitutes an important axis for waste water purification in natural treatment pond(s) in East Kolkata Wetlands. Ecol. Eng. 90:63-67. https://doi. org/10.1016/j.ecoleng.2016.01.056

8. DIBBLE, J.T.; BARTHA, R. 1979. Effect of environmental parameters on the biodegradation of oil sludge. Appl. Environ. Microbiol. 37(4):729-739.

9. DUKE, N.C.; BURNS, K.A.; SWANNELL, R.P.J.; DALHAUS, O.; RUPP, R.J. 2000. Dispersant use and a bioremediation strategy as alternate means of reducing impacts of large oil spills on mangroves:the Gladstone field trials. Mar. Pollut. Bull. 41(7-12):403-412. https:// doi.org/10.1016/S0025-326X(00)00133-8
10. ERMAWATI, R.; MORIMURA, S.; TANG, Y.; LIU, K.; KIDA, K. 2007. Degradation and behavior of natural steroid hormones in cow manure waste during biological treatments and ozone oxidation. J. Biosci. Bioeng. 103(1):27-31. https://doi.org/10.1263/jbb.103.27

11. FANG, F.; QIAO, L.; CAO, J.; LI, Y.; XIE, W.; SHENG, G.; YU, H. 2016. Quantitative evaluation of $A 2 O$ and reversed A2O processes for biological municipal wastewater treatment using a projection pursuit method. Sep. Purif. Technol. 166:164-170. https://doi. org/10.1016/j.seppur.2016.04.036

12. GAO, P.; LI, G.; DAI, X.; DAI, L.; WANG, H.; ZHAO, L.; CHEN, Y.; MA, T. 2013. Nutrients and oxygen alter reservoir biochemical characters and enhance oil recovery during biostimulation. World J. Microbiol. Biotechnol. 29(11):2045-2054. https://doi. org/10.1007/s11274-013-1367-4

13. GARCÍA, S.; VENOSA, A.D.; SUIDAN, M.T.; LEE, K.; COBANLI, S.; HAINES, J.R. 2007. Biostimulation for the treatment of an oil contaminated coastal salt march. Biodegradation. 18(1):1-15. https://doi. org/10.1007/s10532-005-9029-3

14. GONG, X. 2012. Remediation of weathered petroleum oil-contaminated soil using a combination of biostimulation and modified fenton oxidation. Int. Biodeterior. Biodegrad. 70:89-95. https://doi.org/10.1016/j. ibiod.2012.02.004

15. GUO, J.; WANG, J.; CUI, D.; WANG, L.; MA, F.; CHANG, C.; YANG, J. 2010. Application of bioaugmentation in the rapid start-up and stable operation of biological processes for municipal wastewater treatment at low temperatures. Bioresour. Technol. 101(17):66226629. https://doi.org/10.1016/j.biortech.2010.03.093

16. HASSANSHAHIAN, M.; AHMADINEJAD, M.; TEBYANIAN, H.; KARIMINIK, A. 2013. Isolation and characterization of alkane degrading bacteria from petroleum reservoir waste water in Iran (Kerman and Tehran provenances). Mar. Pollut. Bull. 73(1):300-305. https:// doi.org/10.1016/j.marpolbul.2013.05.002

17. HONG, S.U.; OUYANG, L.; BRUENING, M.L. 2009. Recovery of phosphate using multilayer polyelectrolyte nanofiltration membranes. J. Membrane Sci. 327(12):2-5. https://doi.org/10.1016/j.memsci.2008.11.035

18. JI, G.; TONG, J.; TAN, Y. 2011. Wastewater treatment efficiency of a multi-media biological aerated filter (MBAF) containing clinoptilolite and bioceramsite 
in a brick-wall embedded design. Bioresour. Technol. 102(2):550-557. https://doi.org/10.1016/j. biortech.2010.07.075

19. KAHMARK, K.A.; UNWIN, J.P. 1998. Pulp and paper effluent management. Water Environ. Res. 70(4):667690. https://doi.org/10.2175/106143098X134406

20. KUMAR, A.; DHALL, P.; KUMAR, R. 2010. Redefining BOD: COD ratio of pulp mill industrial wastewaters in BOD analysis by formulating a specific microbial seed. Int. Biodeterior. Biodegrad. 64(3):197-202. https://doi.org/10.1016/j.ibiod.2010.01.005

21. KYRIACOU, A.; LASARIDI, K.E.; KOTSOU, M.; BALIS, C.; PILIDIS, G. 2005. Combined bioremediation and advanced oxidation of green table olive processing wastewater. Process Biochem. 40(3-4):1401-1408. https://doi.org/10.1016/j.procbio.2004.06.001

22. LIM, S.; CHU, W.; PHANG, S. 2010. Use of Chlorella vulgaris for bioremediation of textile wastewater. Bioresour. Technol. 101(19):7314-7322. https://doi. org/10.1016/j.biortech.2010.04.092

23. LIU, H.W.; LO, S.N.; LAVALLEE, H.C. 1996. Theoretical study on two-stage anaerobic biological treatment of a CTMP effluent. Part I: effects of operating conditions on system behaviour. Water Qual. Res. J. Can. 31(1):1-19.

24. LU, H.; YUAN, Y.; CAMPBELL, D.E.; QIN, P.; CUI, L. 2014. Integrated water quality, emergy and economic evaluation of three bioremediation treatment systems for eutrophic water. Ecol. Eng. 69:244-254. https:// doi.org/10.1016/j.ecoleng.2014.04.024

25. MARCELINO, R.B.P.; LEÃO, M.M.D.; LAGO, R.M.; AMORIM, C.C. 2017. Multistage ozone and biological treatment system for real wastewater containing antibiotics. J. Environ. Manage. 195(2):110-116. https://doi.org/10.1016/j.jenvman.2016.04.041

26. MARGESIN, R.; SCHINNER, F. 1998. Low-temperature bioremediation of a waste water contaminated with anionic surfactants and fuel oil. Appl. Microbiol. Biotechnol. 49(4):482-486. https://doi.org/10.1007/ s002530051202

27. MARINHO-SORIANO, E.; AZEVEDO, C.A.A.; TRIGUEIRO, T.G.; PEREIRA, D.C.; CARNEIRO, M.A.A.; CAMARA, M.R. 2011. Bioremediation of aquaculture wastewater using macroalgae and Artemia. Int. Biodeterior. Biodegrad. 65(1):253-257. https://doi.org/10.1016/j. ibiod.2010.10.001
28. NANNIPIERI, P.; ASCHER, J.; CECCHERINI, M.T.; LANDI, L.; PIETRAMELLARA, G.; RENELLA, G. 2003. Microbial diversity and soil functions. Eur. J. Soil Sci. 54(4):655-670. https://doi.org/10.1111/ejss.4_12398

29. NI, S.Q.; WANG, Z.; LV, L.; LIANG, X.; REN, L.; ZHOU, Q. 2015. Bioremediation of wastewaters with decabromodiphenyl ether by anaerobic granular sludge. Colloids Surf. B Biointerfaces. 128:522-527. https:// doi.org/10.1016/j.colsurfb.2015.03.003

30. NIEVAS, M.L.; COMMENDATORE, M.G.; ESTEVES, J.L.; BUCALÁ, V. 2005. Effect of pH modification on bilge waste biodegradation by a native microbial community. Inter. Biodeterior. Biodegrad. 56(3):151-157. https://doi.org/10.1016/j.ibiod.2005.06.006

31. NIKOLOPOULOU, M.; KALOGERAKIS, N. 2009. Biostimulation strategies for fresh and chronically polluted marine environments with petroleum hydrocarbons. J. Chem. Tec. \& Biotechn. 84(6):802-807. https://doi. org/10.1002/jctb.2182

32. NTENGWE, F.W. 2005. The cost benefit and efficiency of waste water treatment using domestic ponds - The ultimate solution in Southern Africa. Phys. Chem. Earth. 30(11.16):735-743. https://doi.org/10.1016/j. pce.2005.08.015

33. OSUOLALE, O.; OKOH, A. 2015. Assessment of the physicochemical qualities and prevalence of Escherichia coli and Vibrios in the final effluents of two wastewater treatment plants in South Africa: Ecological and public health implications. Int. J. Environ. Res. Public Health. 12(10):13399-13412. https://doi. org/10.3390/ijerph121013399

34. PREVOST, B.; LUCAS, F.S.; GONCALVES, A.; RICHARD, F.; MOULIN, L.; WURTZER, S. 2015. Large scale survey of enteric viruses in river and waste water underlines the health status of the local population. Environ. Int. 79:383-396. https://doi.org/10.1016/j. envint.2015.03.004

35. QUAN, Y.; HAN, H.; ZHENG, S. 2012. Effect of dissolved oxygen concentration (microaerobic and aerobic) on selective enrichment culture for bioaugmentation of acidic industrial wastewater. Bioresour. Technol.120:1-5. https://doi.org/10.1016/j. biortech.2012.06.019

36. RAJENDRAN, R.; SOORA, M.; DANANJEYAN, B.; RATERING, S.; KRISHNAMURTHY, K.; BENCKISER, G. 2012. Microbial community diversity of organically 
rich cassava sago factory waste waters and their ability to use nitrate and $\mathrm{N} 2 \mathrm{O}$ added as external $\mathrm{N}$-sources for enhancing biomethanation and the purification efficiency. J. Biotechnol. 164(2):266-275. https://doi. org/10.1016/j.jbiotec.2012.11.013

37. RANA, R.; SINGH, P.; KANDARI, V.; SINGH, R.; DOBHAL, R.; GUPTA, S. 2017. A review on characterization and bioremediation of pharmaceutical industries' wastewater: an Indian perspective. Appl. Water Sci. 7(1):1-12. https://doi.org/10.1007/s13201-014-0225-3

38. SALINAS, A.; SANTOS, M.; SOTO, O.; DELGADO, E.; PÉREZ, H.; HÁ UAD, L.A.; MEDRANO, H. 2008. Development of a bioremediation process by biostimulation of native microbial consortium through the heap leaching technique. J. Environ. Manage. 88(1):115119. https://doi.org/10.1016/j.jenvman.2007.01.038

39. SANSCARTIER, D.; LAING, T.; REIMER, K.; ZEEB, B. 2009. Bioremediation of weathered petroleum hydrocarbon soil contamination in the Canadian High Arctic: laboratory and field studies. Chemosphere. 77(8):1121-1126. https://doi.org/10.1016/j. chemosphere.2009.09.006

40. SARATALE, R.G.; SARATALE, G.D.; CHANG, J.S.; GOVINDWAR, S.P. 2011. Bacterial decolorization and degradation of azo dyes: A review. J. Taiwan Inst. Chem. Eng. 42(1):138-157. https://doi.org/10.1016/j. jtice.2010.06.006

41. SARKAR, D.; FERGUSON, M.; DATTA, R.; BIRNBAUM, S. 2005. Bioremediation of petroleum hydrocarbons in contaminated soils: comparison of biosolids addition, carbon supplementation, and monitored natural attenuation. Environ. Pollut. 136(1):187-195. https:// doi.org/10.1016/j.envpol.2004.09.025

42. SODE, S.; BRUHN, A.; BALSBY, T.J.S.; LARSEN, M.M.; GOTFREDSEN, A.; RASMUSSEN, M.B. 2013. Bioremediation of reject water from anaerobically digested waste water sludge with macroalgae (Ulva lactuca, Chlorophyta). Bioresour. Technol. 146:426435. https://doi.org/10.1016/j.biortech.2013.06.062

43. STOLL, A.; DUNCAN, J.R. 1997. Implementation of a continuous-flow stirred bioreactor system in the bioremediation of heavy metals from industrial wastewater. Environ. Pollut. 97(3):247-251. https://doi. org/10.1016/S0269-7491(97)00094-8
44. TANG, H.L.; CHEN, H. 2015. Nitrification at full-scale municipal wastewater treatment plants: Evaluation of inhibition and bioaugmentation of nitrifiers. Bioresour. Technol. 190:76-81. https://doi.org/10.1016/j. biortech.2015.04.063

45. TYAGI, M.; FONSECA, M.M.R.; CARVALHO, C.C.C.R. 2011. Bioaugmentation and biostimulation strategies to improve the effectiveness of bioremediation processes. Biodegradation. 22(2):231-241. https://doi. org/10.1007/s10532-010-9394-4

46. VERMA, R.; SUTHAR, S. 2014. Synchronized urban wastewater treatment and biomass production using duckweed Lemna gibba L. Ecol. Eng. 64:337-343. https:// doi.org/10.1016/j.ecoleng.2013.12.055

47. WANG, C.; ZHENG, S.; WANG, P.; QIAN, J. 2014. Effects of vegetations on the removal of contaminants in aquatic environments: A review. J. Hydrodyn. 26(4):497511. https://doi.org/10.1016/S1001-6058(14)600573

48. WANI, D.; PANDIT A.K.; KAMILI, A.N. 2013. Microbial assessment and effect of seasonal change on the removal efficiency of FAB based sewage treatment plant. J. Environ. Eng. Ecol. Sci. 2:1-4. https://doi. org/10.7243/2050-1323-2-1

49. WEN, D.; ZHANG, J.; XIONG, R.; LIU, R.; CHEN, L. 2013. Bioaugmentation with a pyridine-degrading bacterium in a membrane bioreactor treating pharmaceutical wastewater. J. Environ. Sci. 25(11):2265-2271. https://doi.org/10.1016/S1001-0742(12)60278-2

50. ZAFRA, C.; TEMPRANO, J.; TEJERO, I.; 2017. The physical factors affecting heavy metals accumulated in the sediment deposited on road surfaces in dry weather: A review. Urban Water J. 14(6):639-649. https:// doi.org/10.1080/1573062X.2016.1223320

51. ZHOU, D.; LI, Y.; ZHANG, Y.; ZHANG, C.; LI, X.; CHEN, Z; HUANG, J.; LI, X.; FLORES, G.; KAMON, M. 2014. Column test-based optimization of the permeable reactive barrier (PRB) technique for remediating groundwater contaminated by landfill leachates. J. Contam. Hydrol. 168:1-16. https://doi.org/10.1016/j. jconhyd.2014.09.003

Recibido: Febrero 26 de 2018

Aceptado: Octubre 1 de 2018

Cómo citar:

Ome Barrera, O.; Zafra Mejía, C. 2018. Factores clave en procesos de biorremediación para la depuración de aguas residuales. una revisión. Rev. U.D.C.A Act. \& Div. Cient. 21(2):573-585. https://doi.org/10.31910/rudca.v21.n2.2018.1037 